\title{
Diffuse Peritonitis due to Perforated Gastric Ectopic Pancreas
}

\author{
Nobutada Fukino Takatsugu Oida Kenji Mimatsu \\ Kazutoshi Kida Atsushi Kawasaki Youichi Kuboi \\ Hisao Kano \\ Department of Surgery, Social Insurance Yokohama Central Hospital, \\ Yokohama, Japan
}

\section{Key Words}

Pancreas · Gastric ulcer · Stomach

\begin{abstract}
Ectopic pancreas is frequently found in the gastrointestinal tract. Lesions comprise well-developed and normally organized pancreatic tissue outside the pancreas, without anatomic or vascular connections with the true pancreas. Most patients with ectopic pancreas are asymptomatic or exhibit nonspecific symptoms. A 68-year-old Japanese woman had been experiencing intermittent pain in the right upper abdomen. Suddenly, the abdominal pain changed to intense pain in the right flank of the abdomen 2 days later. On initial medical examination, the abdomen exhibited rebound tenderness and distension. The results of laboratory tests revealed increased inflammatory reaction. Abdominal computed tomography showed free air and ascites on the surface of the liver and elevated levels of adipose tissue around the antrum and pylorus of the stomach. Perforation of the upper gastrointestinal tract was diagnosed and we performed urgent surgery. The site of perforation, whose size was $25 \mathrm{~mm}$, was the lesser curvature of the antrum of the stomach. Since it was not possible to perform omentopexy, we performed extensive gastric resection. The reconstruction was a Billroth II operation. Microscopic analysis revealed pancreatic tissue within the ulceration, showing islets of Langerhans, acini, and ducts; the lesion was diagnosed as type I using Heinrich's criteria. The postoperative course was uneventful. The patient was discharged on day 13 and remains clinically healthy. Gastric perforation due to ectopic pancreas has been reported in 2 cases, including our patient, and is extremely rare. Once gastric perforation has been diagnosed, the presence of ectopic pancreas might be considered.
\end{abstract}




\section{Introduction}

Ectopic pancreas is generally well-developed and normally organized pancreatic tissue located outside the pancreas, without anatomic or vascular connections with the true pancreas. The incidence of ectopic pancreas at all sites has been estimated to be $0.55-13.7 \%$ in an autopsy series [1]. The incidence of ectopic pancreas of all removed specimens is $0.25 \%$, and in the gastrointestinal tract, with $24-38 \%$ in the stomach, $9-36 \%$ in the duodenum, and $0.5-27 \%$ in the jejunum $[2,3]$.

Patients with ectopic pancreas are asymptomatic or exhibit nonspecific symptoms, and the condition is often found secondary to other conditions, such as neoplastic transformation [4], intussusception [5], acute pancreatitis [6, 7] and pseudocyst [2]. Perforation of the stomach due to ectopic pancreas has been reported in only 2 cases, including our patient, in PubMed from 1963 to June 2012.

The gastric ectopic pancreas is located in the antrum in $85-95 \%$ of cases and categorized in the classification by Heinrich. Histological examination revealed pancreatic tissue with acini, ducts, and islets of Langerhans between the muscular layer and subserosa around the ulceration, categorized as type I of Heinrich's classification. Reports on surgery for perforated gastrointestinal tract due to ectopic pancreas are extremely rare. Here we report an extremely rare case of ectopic pancreas that developed into a perforated gastric ulcer.

\section{Case Report}

A 68-year-old Japanese woman with hypertension and hyperlipemia consulted a general practitioner after experiencing intermittent pain in the right upper abdomen. She suddenly felt intense pain in the right flank of the abdomen and was taken to the nearest hospital. Upper gastrointestinal tract perforation was diagnosed by abdominal computed tomography, and she was transferred to our hospital. On initial medical examination, the abdomen exhibited rebound tenderness and distension of the abdominal whole. Temperature, blood pressure and heart rate were 37.0 degrees, 137/70 mm Hg and 77 beats/min, respectively. Complete blood count, coagulation test and laboratory analysis performed on admission revealed the following values (normal range in parentheses): white blood cells, $12,770 / \mu \mathrm{l}(3,200-9,000)$; hemoglobin, $11.9 \mathrm{~g} / \mathrm{dl}$ (11.3-15.2); hematocrit, 36.1\% (33.0-45.0); platelets, $56.5 \times 10^{4} / \mu \mathrm{l}(15.0-33.0)$; prothrombin time, $12.3 \mathrm{~s}(12.0-15.0)$; activated partial thromboplastin time, $28.0 \mathrm{~s}(26.0-36.0) ;$ fibrinogen, $484 \mathrm{mg} / \mathrm{dl}$ (150-350); blood fibrin degradation product, $7.0 \mu \mathrm{g} / \mathrm{ml}(0.0-5.0)$; D-dimer, $2.38 \mu \mathrm{g} / \mathrm{ml}(0.0-25.0)$; total protein, $6.3 \mathrm{~g} / \mathrm{dl}$ (6.5-8.1); albumin, $2.7 \mathrm{~g} / \mathrm{dl}$ (3.8-5.1); blood urea nitrogen, $23.0 \mathrm{mg} / \mathrm{dl}$ (7.0-21.0); creatinine, $0.44 \mathrm{mg} / \mathrm{dl}$ (0.4-0.8); AST, 19 IU (12-32); ALT, 17 IU (10-70); alkaline phosphatase, 311 IU (109-335); $\gamma$-glutamyl transpeptidase, 135 IU (12-48); serum solids, $133 \mathrm{mEq} / \mathrm{l}$ (137-147); serum chloride, $98 \mathrm{mEq} / \mathrm{l}$ (99-109); serum potassium, $3.5 \mathrm{mEq} / \mathrm{l}$ (3.5-4.8); C-reactive protein, $1.84 \mathrm{mg} / \mathrm{dl}(0.00-0.30)$. Blood examination revealed slight inflammatory reaction and slight dehydration, and electrolytes were abnormal. The findings of chest and abdominal radiography were normal. Abdominal computed tomography showed free air and ascites on the surface of the liver, and elevated levels of adipose tissue around the antrum and pylorus of the stomach (fig. 1). We diagnosed perforated upper gastrointestinal tract and performed urgent surgery.

Intraoperative examination revealed that the site of perforation (size $25 \mathrm{~mm}$ ) was the lesser curvature of the antrum of the stomach ( $\underline{\mathrm{fig}}$. 2). Since it was not possible to perform omentopexy, we performed extensive gastric resection. The reconstruction was a Billroth II operation. On macroscopic examination, the location of the ulceration with perforation (dimensions $30 \times 40 \mathrm{~mm}$ ) was confirmed as the lesser curvature of the antrum of the stomach. Microscopic examination revealed that pancreatic tissue within the ulceration showed islets of Langerhans, acini, and ducts. Considering the circumstances mentioned above, the heterotopia pancreas was diagnosed as type I by Heinrich's 
criteria (fig. 3 ). The postoperative course was uneventful, and the patient was discharged on day 13 and remains clinically healthy.

\section{Discussion}

Ectopic pancreas, first reported by Shultz in 1727 [8], is also called heterotopic, heterotropic or aberrant pancreas, and is frequently found in the gastrointestinal tract. The incidence of ectopic pancreas is $0.25 \%$ based on findings from all abdominal surgeries [3]. Ectopic pancreas most commonly develops in the gastrointestinal tract, with $24-38 \%$ in the stomach, $9-36 \%$ in the duodenum, and $0.5-27 \%$ in the jejunum [2], and rare cases are reported in the common bile duct, gallbladder, esophagus, lung, mediastinum, Vater's papilla, mesentery, mesocolon and omentum [3,9-11].

Histopathological examination shows that gastric ectopic pancreas is located in the antrum in $85-95 \%$ of cases, and its incidence in the submucosal, muscularis and subserosal layers is 73,17 and $10 \%$, respectively [12]. The classification of ectopic pancreas proposed by Heinrich [13] is used worldwide. Type I exhibits ectopic tissue with acini, ducts, and islets of Langerhans. Type II exhibits ectopic tissue with incomplete or lobular arrangement (only a few acini and multiple ducts), and endocrine elements are absent. Type III comprises ectopic tissue of proliferating ducts (so-called adenomyoma), with neither acini nor endocrine elements. The microscopic perspective of Gurocak et al. [12] revealed intramurally located dilated pancreatic ducts and acini (type II of Heinrich's classification). Histological examination of our case showed an ulceration measuring $30 \times 40 \mathrm{~mm}$ at the antrum of the stomach; pancreatic tissue with acini, ducts, and islets of Langerhans was found between the muscular layer and subserosa around the ulceration. Therefore, this ectopic pancreas was categorized as type I, and the gastric perforation was found to be caused by ectopic pancreatitis.

Most patients with ectopic pancreas are asymptomatic or exhibit nonspecific symptoms such as abdominal pain, nausea, vomiting and hemorrhage [2]. Ectopic pancreas is found rarely in association with neoplastic transformation [4], intussusception [5], acute pancreatitis [6, 7] and pseudocyst [2]. To date, as few as 4 cases of gastrointestinal perforation developing secondary to ectopic pancreas have been reported in PubMed (key words: ectopic (heterotopic, aberrant) pancreas, perforation; target period: 1963 to June 2012). Perforation due to ectopic pancreas is found in the duodenal diverticulum [14] and small intestine [15]; gastric perforation due to ectopic pancreas [12] is quite rare. The 5 patients, including our patient, required urgent surgery, and perforation due to ectopic pancreas was diagnosed on the basis of pathological findings. It is not possible to prove through preoperative examination that a gastric perforation is caused by ectopic pancreas. Gastric perforation due to ectopic pancreas has occurred in only 1 of the 5 reported cases of perforation and is an extremely rare condition. Gurocak et al. [12] first reported gastric perforation by heterotopic pancreas. In that case, the size of ulceration in the gastric antrum and the perforation were $35 \times 30 \mathrm{~mm}$ and $10 \mathrm{~mm}$, respectively. In our case, the ulceration and perforation were located at the anterior wall of the antrum in the stomach and measured $30 \times 40 \mathrm{~mm}$ and $25 \mathrm{~mm}$, respectively. The location and size of the ulceration were similar, but the size of the perforation was bigger in our case. 
In conclusion, diagnosis of ectopic pancreas is extremely difficult during preoperative examination in patients with diffuse peritonitis due to perforated gastric ulcer. To our knowledge, this is just the second case of a patient with diffuse peritonitis due to perforated gastric ectopic pancreas. During preoperative diagnosis of a perforated gastrointestinal tract, it is suggested that ectopic pancreatic tissue be considered as a cause, especially in cases of gastric perforation.

\section{Disclosure Statement}

The authors have no potential conflicts of interest.

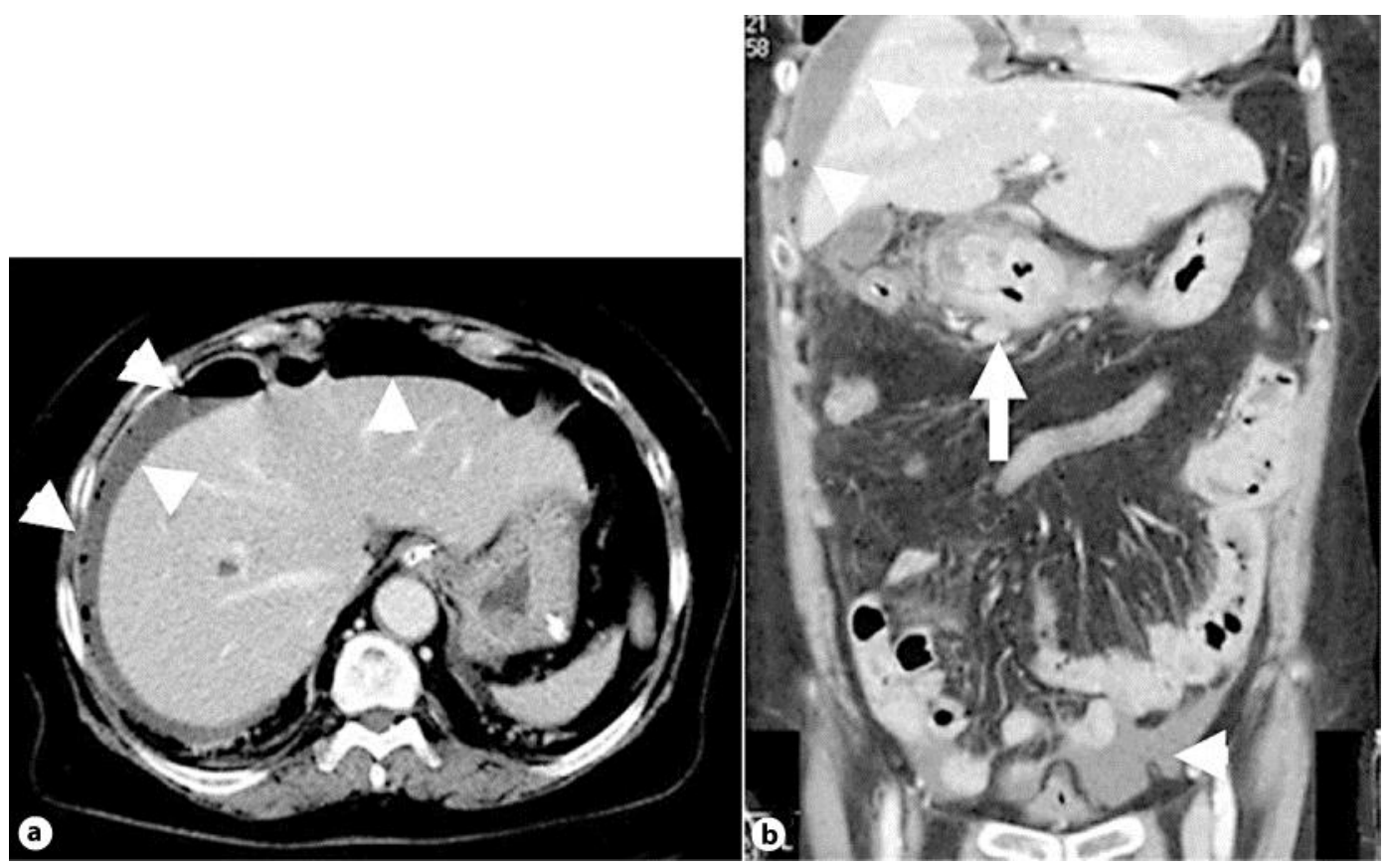

Fig. 1. Enhanced abdominal computed tomography showed free air and ascites on the face of the liver and at the Douglas pouch ( $\mathbf{a}, \mathbf{b}$; arrowheads). Levels of adipose tissue around the antrum and pylorus of the stomach revealed increase. Moreover, a thickened wall extended from the antrum of the stomach to the duodenal bulb (b) (arrow). 


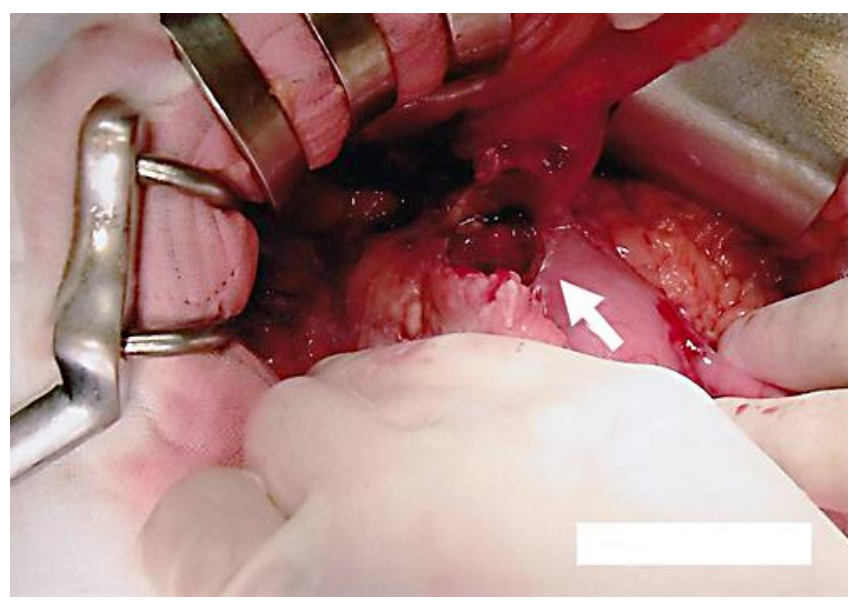

Fig. 2. Perforation in the lesser curvature of the antrum of the stomach measuring $25 \mathrm{~mm}$ (arrow).

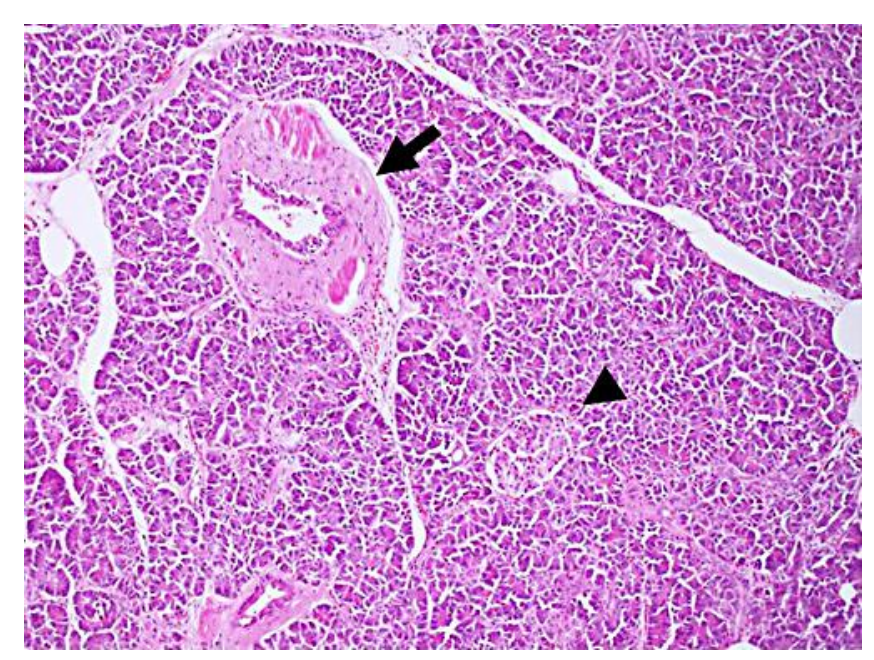

Fig. 3. Histological examination of the resected specimen showed islets of Langerhans (arrowhead), ducts (arrow) and acini (hematoxylin and eosin stain, $\times 100$ ). Classification by Heinrich's criteria was type I.

\section{References}

1 Fukumori D, Matsuhisa T, Taguchi K, Minato M: Ectopic gastric pancreatic cancer: report of a case. Hepatogastroenterology 2011;58:740-744.

$\checkmark 2$ Sharma DK, Agarwal S, Saran RK, Agarwal AK: Pseudocyst of ectopic pancreas of the duodenal wall masquerading as malignant cystic tumor of pancreas. Saudi J Gastroenterol 2009;15:271-273.

-3 Tanaka K, Tsunoda T, Eto T, et al: Diagnosis and management of heterotopic pancreas. Int Surg 1993;78:32-35.

-4 Osanai M, Miyokawa N, Tamaki T, Yonekawa M, Kawamura A, Sawada N: Adenocarcinoma arising in gastric heterotopic pancreas: clinicopathological and immunohistochemical study with genetic analysis of a case. Pathol Int 2001;51:549-554.

5 Carleton CC, Ackerbaum R: Intussusception secondary to aberrant pancreas in a child. JAMA 1976;236: 1047. 
-6 Fam S, O’Brian DS, Borger JA: Ectopic pancreas with acute inflammation. J Pediatr Surg 1982;17:86-87.

7 Green PH, Barratt PJ, Percy JP, Cumberland VH, Middleton WR: Acute pancreatitis occurring in gastric aberrant pancreatic tissue. Am J Dig Dis 1977;22:734-740.

8 Papaziogas B, Koutelidakis L, Tsiaousis P, et al: Carcinoma developing in ectopic pancreatic tissue in the stomach: a case report. Cases J 2008;1:249.

$\checkmark 9$ Kaneda M, Yano T, Yamamoto T, Suzuki T, Fujimori K, Itoh H, Mizumoto R: Ectopic pancreas in the stomach presenting as an inflammatory abdominal mass. Am J Gastroenterol 1989;84:663-666.

10 Tornóczky T, Kálmán E, Jáksó P, et al: Solid and papillary epithelial neoplasm arising in heterotopic pancreatic tissue of the mesocolon. J Clin Pathol 2001;54:241-245.

11 Pavlović S, Janjić D, Mihajlović S, et al: Cytochemical and immunocytochemical characteristics of Meckel's diverticulum with heterotopic rests of pancreatic tissue. Vojnosanit Pregl 2010;67:1021-1024.

12 Gurocak B, Gokturk HS, Kayacetin S, Bakdik S: A rare case of heterotopic pancreas in the stomach which cased closed perforation. Neth J Med 2009;67:285-287.

13 von Heinrich H: Ein Beitrag zur Histologie des sogen. akzessorischen Pankreas. Virchows Arch A Pathol Anat Histopathol 1909;198:392-401.

14 Gunjaca I, Mlinac-Lucijanić M, Pavlović A, Gunjaca M: Inflammation of ectopic pancreatic tissue as unusual cause of duodenal perforation - a case report. Coll Antropol 2010;34:1119-1122.

15 Pal K, Ashri H, Madani AA: Intestinal perforation by multiple ectopic pancreatic tissues in a neonate with multiple congenital anomalies. Saudi Med J 2008;29:614-616. 